\title{
Phosphate Solubilization Activity of Rhizobial Strains Isolated From Root Nodule of Cluster Bean Plant Native to Indian Soils
}

\author{
Subha Dhull ${ }^{1}$, Rajesh Gera ${ }^{1}$, Hardeep Singh Sheoran ${ }^{2 *}$ and Ridham Kakar ${ }^{2}$ \\ ${ }^{1}$ Departmentof Microbiology, CCS Haryana Agricultural University, Hisar-125004, \\ Haryana, India \\ ${ }^{2}$ Haryana Space Applications Center, CCS HAU Campus, Hisar-125004, Haryana, India \\ *Corresponding author
}

\begin{tabular}{|l|}
\hline Ke y w o r d s \\
Cluster bean, Rhizobium, \\
$\begin{array}{l}\text { P-solubilization, } \\
\text { Biofertilizer and } \\
\text { Sustainable agriculture }\end{array}$ \\
\hline Article Info \\
\hline $\begin{array}{l}\text { Accepted: } \\
\text { 04 March } 2018 \\
\text { Available Online: } \\
\text { 10 April 2018 }\end{array}$ \\
\hline
\end{tabular}

\section{A B S T R A C T}

Cluster bean (Cyamopsis tetragonoloba L.) is an important legume crop of India which can thrive well in adverse conditions. Despite of the fact that $\mathrm{P}$ is abundant in the soil it cannot be assessed by plants. Bacteria like rhizobium isolated from root nodules have potential to solublize the insoluble phosphorus. Thus, it plays a vital role in enhancing the phosphorus availability and overcoming phosphorus deficiency through its transformations into available form and thereby enhancing the agricultural productivity in a sustainable way. Soil samples were collected from the fields located at three districts of Haryana. Further isolation and characterization of rhizobial isolates was carried out in screen house and phosphorus soulbilization efficiency was measured. A total of 14 rhizobial strains were isolated from the root nodules of cluster bean which was collected from different villages of Haryana. On the basis of morphologically, biochemically, they were recognized as rhizobia. All isolates were tested for the phosphate solubilization on YEMA and Pikovaskaya's medium plates. Among 14 rhizobial isolates, 7 were found to solubilize phosphorus efficiently after 7 days of incubation at $30^{\circ} \mathrm{C}$, however their P- solubilization efficiency varied from 36 to $79 \%$. These rhizobial strains were observed to be efficient in solubilizing the phosphate. As rhizobia can act as a phosphate-solubilizer along with nitrogen fixation makes these strains efficient to be utilized for the production of biofertilizers, which can improve the availability of major growth limiting nutrients like phosphorus in soil and enhances the agricultural production.

\section{Introduction}

Cluster bean or guar (Cyamopsis tetragonoloba L.) is an important legume crop which is drought and salinity tolerant (Francois et al., 1990, Ashraf et al., 2005, Gresta et al., 2014). Guar enhances the available nitrogen and organic carbon content in soils by adding substantial amount of nitrogen through fixation of atmospheric nitrogen and adding crop residues (Elsheikh and Ibrahim, 1999, Kalyani, 2012). India is one of the major producers of guar which along with Pakistan accounts for about $80 \%$ of total world's production. In India, Haryana and Rajasthan occupy the largest area of $82.1 \%$ (Pathak et al., 2010). Guar is a short season crop of about 90-120 days (Undersander et al., 
1991) which makes it a viable crop that can be included in rotation (Tucker and Foraker, 1975) with other long duration crops such as cotton, vegetables etc (Tripp et al., 2011). However, in present day intensive agriculture, soils are far away from being ideal in terms of productivity due to over exploitation of these natural resources and hence Indian soils are deteriorating in there available macro and micronutrients status particularly in relation to nitrogen and phosphorus, which are essential for obtaining optimum crop productivity. Phosphorus is one of the essential macronutrient required for plant growth, which has no source in atmosphere as in case of nitrogen (Khan et al., 2009). Most of the soils contain phosphorus but major portion of it is present in unavailable form that may be organic or in fixed form and hence its availability to plants is very low and thereby adversely affecting plant growth. Phosphorus in Indian soils mainly occurs in the form of phosphate rock deposits and is the only cheapest source of phosphorus fertilizer for crop production (Rodriguez and Fraga, 1999). Large amount of phosphorous applied to the soil as fertilizer gets fixed into immobile form through precipitation with metal ions like $\mathrm{Al}^{3+}$ and $\mathrm{Fe}^{3+}$ in acidic soils and $\mathrm{Ca}^{2+}$ in alkaline or normal soils (Khan et al., 2009). Hence, despite of the fact that $\mathrm{P}$ is present in abundance in the soil but largely in insoluble form such as tricalcium phosphate etc and it is cannot be assessed by plant roots. Thus, microorganisms like phosphate solubilizing bacteria can play a vital role in enhancing the phosphorus availability and overcoming phosphorus deficiency in soil through its transformations into available form (Antoun, 2012). Bacterial genera's having the potential ability to solublize phosphorus include Rhizobium, Pseudomonas, Bacillus, Flavobacterium, Achromobacter, Agrobacterium, Microccocus, Burkholderia, Erwinia (Rodríguez and Fraga, 1999) while Perez et al., 2007 also reported Serratia,
Ralstonia, andPantoeaas potential $\mathrm{P}$ solubilizers and Ewingella, Enterobacter and Photorhabdus were reported as efficient microbes in $\mathrm{P}$ availability by Ribeiro and Cardoso, 2012 and Ullah et al., 2013. There may be several mechanisms by which $\mathrm{P}$ solubilization takes place but one major is through the production of organic acids and these acids can solubilize insoluble forms of phosphate to available forms which can enhance availability of phosphorus to plants (Nautiyal, 1999). Such groups of bacteria are abundant in rhizospheres and accounts for the proliferation and metabolisms of numerous types of microorganisms (Jadhav, 2013) and are reported to have the ability to solubilize insoluble forms of phosphorus in soils (Rodriguez and Fraga, 1999). Moreover, bacteria are more effective in soluilizing phosphorus than fungi (Alam et al., 2002). Phosphate solubilizing bacteria not only includes the free living forms but also encompasses the symbiotic bacteria like Rhizobium, Mesorhizobium, Bradyrhizobium (Peix et al., 2001). Symbiotic nitrogen fixing bacteria are advantageous than free living soil microbes in phosphorous solubilization because these are protected inside the nodule formed in crop roots and face little competition with indigenous rhizospheric microflora. Microorganisms such as rhizibium are capable of stimulating the growth of legume crops and are able supply nitrogen in plant available form to soil by fixing atmospheric nitrogen into soil through symbiotic association with host plants, in the presence of enzyme nitrogenase (Kiers et al., 2003). Moreover, rhizobia are reported to have high phosphate solubilizing potential in solubilizing both organic and inorganic phosphates and are preferred over others by virtue of their duel role in nitrogen fixation and $\mathrm{P}$ solubilization (Alikhani et al., 2006; Ruzhen and Peng, 2010). Because of the advantage that rhizobia can act as a phosphate-solubilizer along with nitrogen 
fixation makes it efficient to be used in preparation of biofertilizers. Biofertilizers now-a-days are becoming popular for their use in agriculture because of their efficiency to maintain a good soil health, minimizing environmental pollutions along with availability of major nutrients which critically affect the plant growth. Keeping in view the above concerns, the present study deals with the isolation of 14 rhizobial strains from root nodules of cluster bean and testing their ability to solubilize tricalciumphosphate (TCP), so that these can be efficiently used for the production of biofertilizers.

\section{Materials and Methods}

\section{Collection of soil samples}

Soil samples were collected from the different fields located at three districts of Haryana state namely, Hisar, Bhiwani and Mahendergarh. The different sampling sites are represented in Figure 1. Further isolation and characterization of rhizobial isolates from cluster bean root nodules was carried out in screen house at the Department of Microbiology, CCS Haryana Agricultural University, Haryana, India

Isolation of native rhizobia nodulating cluster bean using trap plant method

Five seeds of cluster bean [Cyamopsis tetragonoloba (L) Taub.] were grown in pots and at later stage three healthy plants were left and rest were removed by thinning process. Each pot contains $2 \mathrm{~kg}$ soil collected from South-Western Haryana to trap the rhizobia nodulating cluster bean. After 45 days of growth when proper nodule formation took place the healthy pink nodules were removed separately from each host plant and were surface sterilized by using $0.1 \% \mathrm{HgCl}_{2}$ and $70 \%$ ethanol (Fig. 2). After that the nodules were washed (5-6 times) with sterilized distilled water and crushed. A loopful of nodule sap was streaked on YEMA plates containing Congo red dye (Vincent, 1970). The plates were incubated at $30^{\circ} \mathrm{C}$ and growth was observed daily for 3-7 days. The rhizobial isolates were picked up from the plates and were restreaked for purification (Fig. 2). Single rhizobial pure isolates were picked up from the plates and maintained on YEMA slants. The slants were stored at $4^{\circ} \mathrm{C}$ in a refrigerator for further studies.

\section{Characterization of rhizobial isolates by Gram's staining and peptone water tests}

All the fourteen cluster bean rhizobial isolates obtained from nodules were characterized for Gram staining and peptone water test to check the authenticity of rhizobia. The isolates were inoculated individually in different peptone water containing tubes and incubated at $30^{\circ} \mathrm{C}$ for 3-4 days (Fig. 3).

\section{Biochemical characterization of rhizobial isolates}

Each rhizobia isolates were then identified on the basis of its growth rate, color, shape and gum production.

\section{Characterization of rhizobial isolates for PGP traits}

\section{Phosphate solubilization}

The ability of rhizobial isolates to solubilize tricalcium phosphate (TCP) was tested on Pikovskaya's medium containing $0.5 \%$ of TCP as insoluble phosphate source (Pikovskaya, 1948). The halo zone formed surrounding the colony revealed phosphate solubilization and was expressed as solubilization efficiency (\%) (Fig. 4). The phosphate solubilization efficiency was computed by using the following equation given below: 
Phosphate Solubilization (Efficiency \%) = $\frac{\text { Solubilization diameter }}{\text { Colony diameter }} \times 100$

(Gothwal et al., 2006)

\section{Results and Discussion}

Phosphate solubilizing rhizobacteria improves the soil fertility by solubilizing native phosphate in soils to the plants. The population of rhizobcteria is dependent on the host plants, soil chemical parameters and management practices. Agricultural crops have created highly selective and homogenous environments that determine the bacterial diversity.

In the present investigation because of poor nodulation in the fields, a total of fourteen soil samples were collected from semi-arid zones of Haryana state. These soil samples were collected from cluster bean fields from different villages located at Hisar, Bhiwani and Mahendergarh districts of Haryana (Table 1).

\section{Physico-chemical properties of soil samples collected from semi-arid zones of Haryana}

It is necessary to check the chemical properties of the soil samples as they affect the growth and nutrient uptake of the plants. These soil samples were analyzed for $\mathrm{pH}, \mathrm{EC}$, organic $\mathrm{C}$ and available N. Soil $\mathrm{pH}$ ranged from 6.7-8.5 among the different samples while EC was in the range of 0.07-0.67 $\mathrm{d} \mathrm{Sm}^{-}$ 1 .

The organic $\mathrm{C}$ varied from $0.15-0.67 \%$ and available $\mathrm{N}$ in soils was found to be low and varied from $80-145 \mathrm{~kg} \mathrm{ha}^{-1}$ (Table 2). For above purpose, rhizospheric soil samples were tried to be collected from cluster bean field from different villages of Hisar, Bhiwani, and Mahendergarh districts of Haryana State. The possible reason for low organic carbon in experimental soils may be due to the reason that soil organic carbon content have a significantly positive and linear correlation with percent silt+clay contents of soils and which are low in sand textured soils. Secondly, it is well established that lighttextured soils are suffering from nutrient deficiency along low organic carbon content (Shaaban et al., 2016). Hence it is clear that sandy soils are low in organic carbon which was reflected in its physico-chemical properties such as low soil organic carbon and other macronutrients contents in soils.

\section{Isolation of rhizobia nodulating cluster bean using trap plants}

The bacteria belonging to nitrogen fixing group can be isolated directly from the nodules of roots of the plant or from the soil (Geniaux et al., 1993), using yeast extract mannitol media (YEMA) (Handley et al., 1998; Castro et al., 2003; Kucuk et al., 2006). The seeds of cluster bean (HG-563 variety) were sown in 39 pots containing $2 \mathrm{~kg}$ of each soil sample and each pot was containing three cluster bean plants. Out of these, the nodule formation was observed only in 32 pots. After 45 days of growth, when nodule formation took place on the roots of cluster bean plants, 2 or 3 healthy pink nodules were collected from each plant and surface sterilized by using $0.1 \% \mathrm{HgCl}_{2}$ and $70 \%$ ethanol as described in material and methods section.

The nodules were crushed and streaked on YEMA medium plates containing Congo red dye. The colonies from each nodule were purified by streaking 2-3 times on same media. In total 14 rhizobial isolates were obtained and these isolates were further purified and maintained on YEMA slants for further studies (Fig. 1). A similar work of isolation of rhizobial strains using yeast extract mannitol agar medium (YEMA) was also carried out by other researchers (Srivastava et al., 2004 and Jadhav, 2013). 


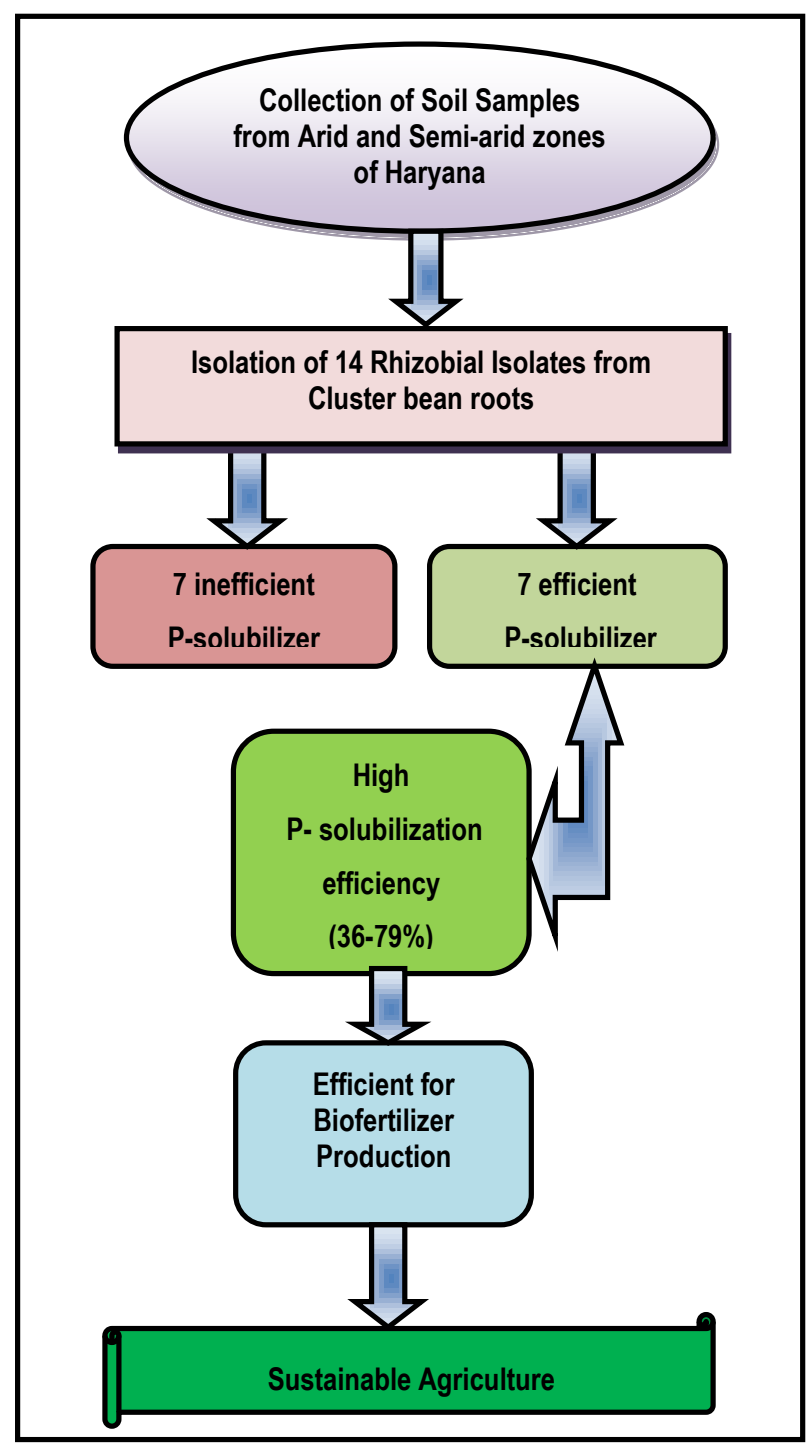

Fig.1 Location map of the sampling sites at different locations of Haryana

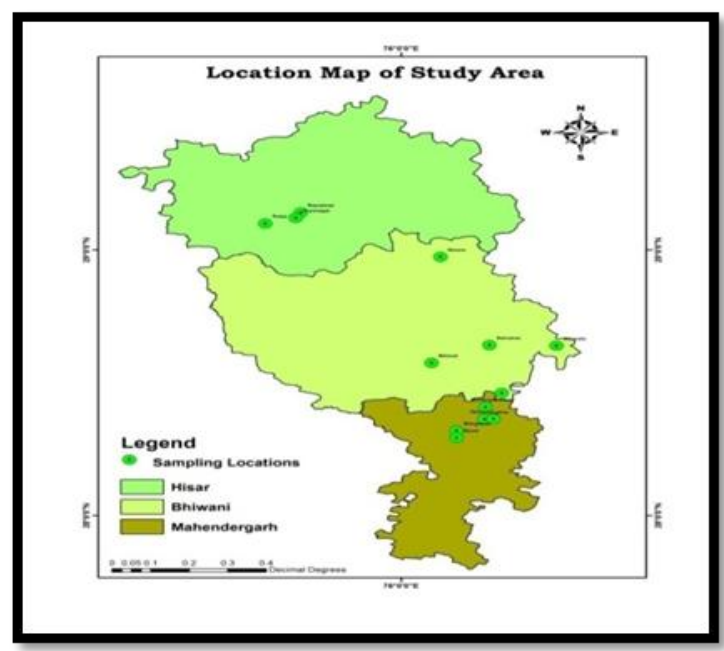


Fig.2 Isolation of rhizobia nodulating cluster bean using trap plants from different districts of south-western Haryana

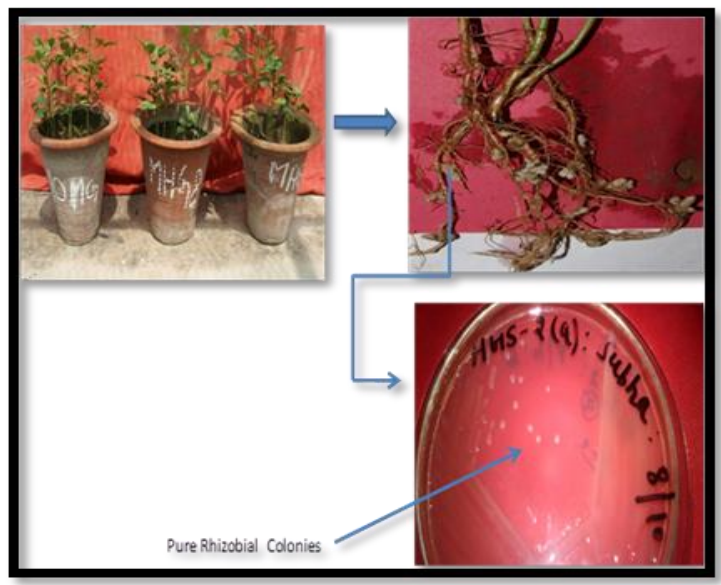

Fig.3 Morphological characterization of cluster bean rhizobial isolates using Gram staining and peptone water test

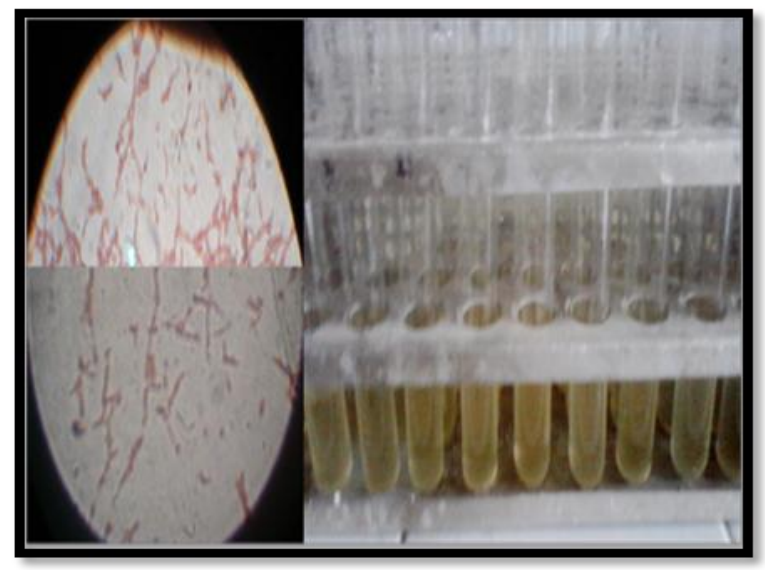

Fig.4 P-solubilization by rhizobial isolates

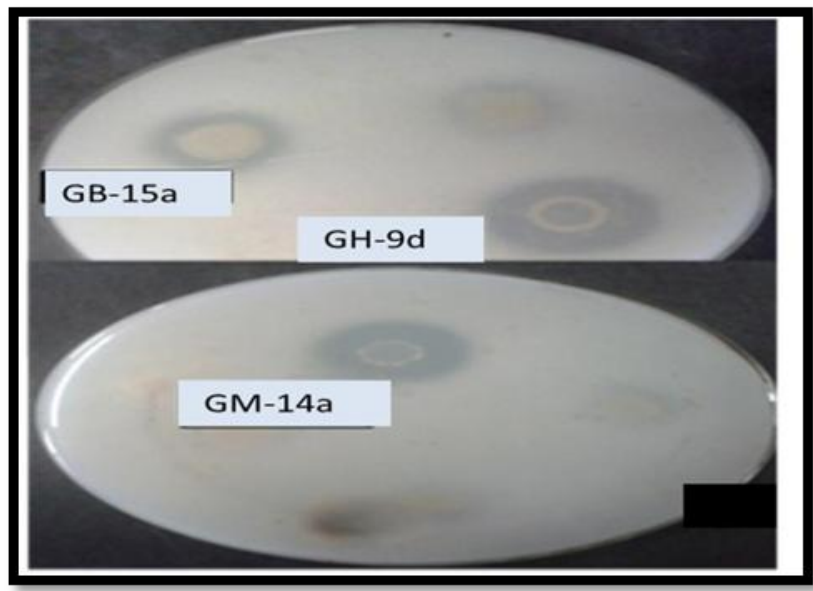


Fig.5 Categorization of rhizobial isolates for P-solubilization

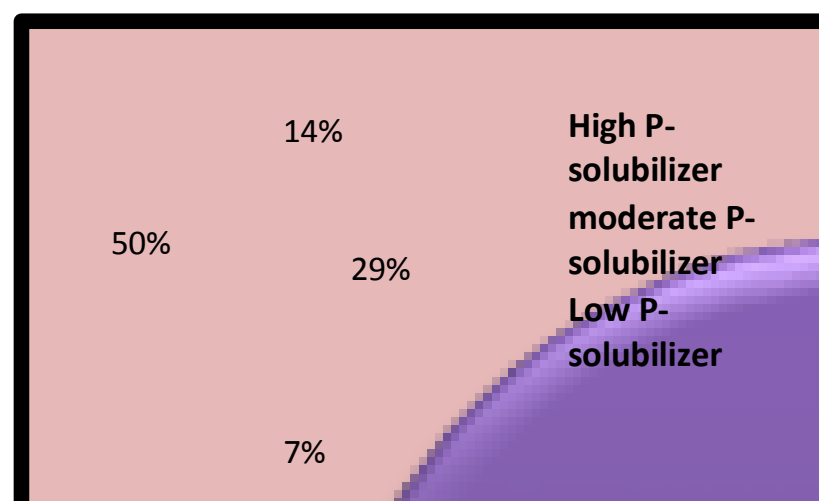

Fig.6 The spatial variability map of P-solubilization among the sampling sites on Pikovskaya's and YEMA growth media in Hisar district of Haryana
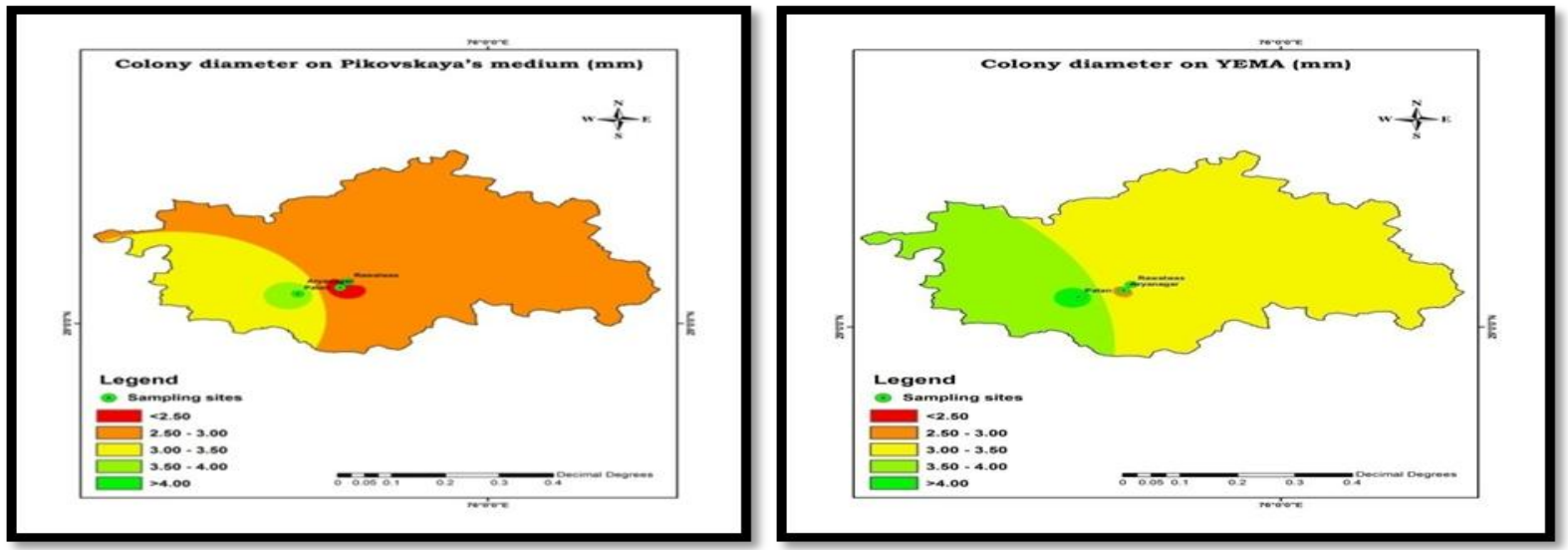

Fig.7 The spatial variability map of P-solubilization among the sampling sites on Pikovskaya's and YEMA growth media in Bhiwani district of Haryana
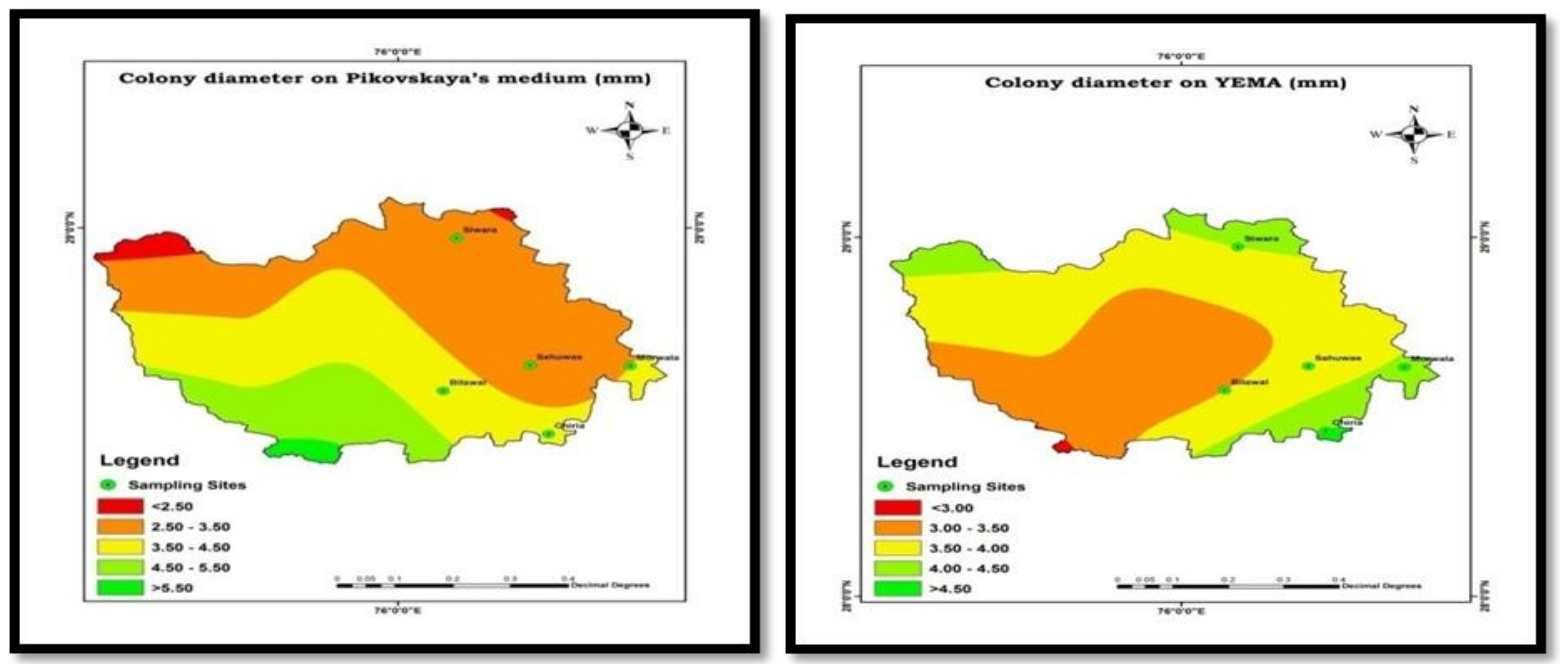
Fig.8 The spatial variability map of P-solubilization among the sampling sites on Pikovskaya's and YEMA growth media in Mahendergarh district of Haryana
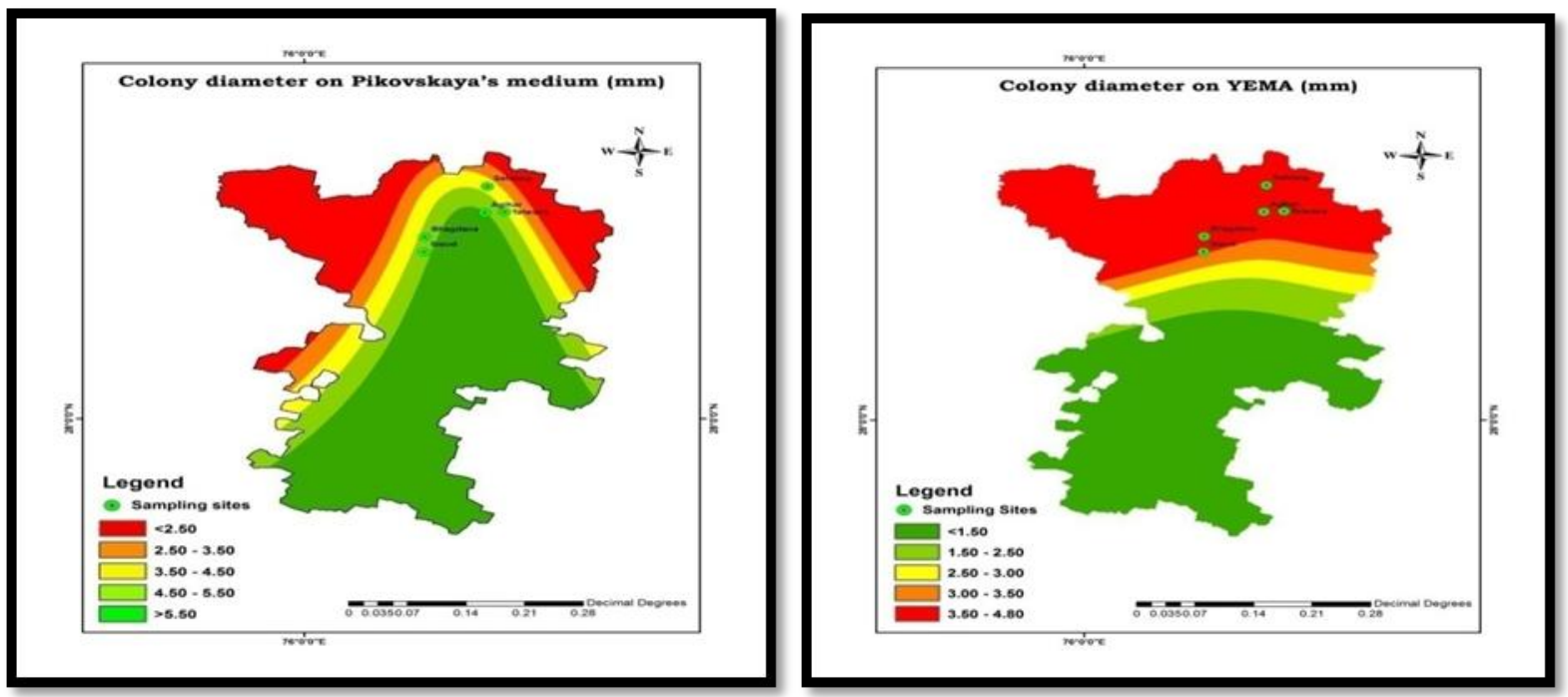

Table.1 Nomenclature of rhizobial isolates and description of different sites

\begin{tabular}{|c|l|l|l|}
\hline Sr. No. & Rhizobia isolates & Village & Districts \\
\hline 1 & GB-11a & Chiria & Bhiwani \\
\hline 2 & GB-13a & Swarh & Bhiwani \\
\hline 3 & GB-14a & Morwala & Bhiwani \\
\hline 4 & GB-15a & Sahuwas & Bhiwani \\
\hline 5 & GB-16a & Bilawal & Bhiwani \\
\hline 6 & GH-1a & Rawalwas & Hisar \\
\hline 7 & GH-9d & Patan & Hisar \\
\hline 8 & GH-10b & Arya-Nagar & Hisar \\
\hline 9 & GM-3a & Sehlang & Mahendergarh \\
\hline 10 & GM-3b & Sehlang & Mahendergarh \\
\hline 11 & GM-4a & Agihar & Mahendergarh \\
\hline 12 & GM-7a & Bhagdana & Mahendergarh \\
\hline 13 & GM-11a & Talwana & Mahendergarh \\
\hline 14 & GM-14a & Sisod & Mahendergarh \\
\hline
\end{tabular}

Table.2 Physico-chemical properties of the soils collected from different districts of Haryana

\begin{tabular}{|l|l|l|l|l|}
\hline District & $\mathrm{pH}$ & $\mathrm{EC}\left(\mathbf{d ~ S m}^{-1}\right)$ & $\mathrm{OC}(\%)$ & $\mathbf{N}\left(\mathrm{kg} \mathrm{ha}^{-1}\right)$ \\
\hline Bhiwani & $6.8-8.5$ & $0.10-0.67(0.30)$ & $0.15-0.48(0.28)$ & $80-114(90)$ \\
\hline Hisar & $6.7-7.5$ & $0.07-0.65(0.36)$ & $0.33-0.48(0.39)$ & $84-140(115)$ \\
\hline Mahendergarh & $6.8-8.5$ & $0.08-0.66(0.33)$ & $0.18-0.67(0.38)$ & $82-145(111)$ \\
\hline Overall range & $6.7-8.5$ & $0.07-0.67$ & $0.15-0.67$ & $80-145$ \\
\hline Overall mean & - & 0.33 & 0.35 & 105 \\
\hline
\end{tabular}


Table.3 Solubilization of tricalcium phosphate by various isolated rhizobial strains collected from different districts of Haryana state

\begin{tabular}{|c|c|c|c|c|c|c|c|}
\hline S. No. & $\begin{array}{l}\text { Rhizobial } \\
\text { isolates }\end{array}$ & $\begin{array}{l}\text { Incubatio } \\
\text { n time } \\
\text { (days) }\end{array}$ & $\begin{array}{l}\text { Colony diameter } \\
\text { on Pikovskaya's } \\
\text { medium (mm) }\end{array}$ & $\begin{array}{l}\text { Colony diameter } \\
\text { on YEMA (mm) }\end{array}$ & $\begin{array}{l}\text { Diameter of zone } \\
\text { of solubilization } \\
(\mathrm{mm})\end{array}$ & $\begin{array}{l}\text { Solubilization } \\
\text { Efficiency }(\%)\end{array}$ & $\begin{array}{l}\text { Final pH of the } \\
\text { medium }\end{array}$ \\
\hline 1 & GB-11a & 7 & 3.8 & 4.5 & 5.2 & 36 & 6.2 \\
\hline 2 & GB-13a & 7 & 2.7 & 4.0 & - & - & - \\
\hline 3 & GB-14a & 7 & 3.5 & 4.1 & 5.0 & 42 & 6.0 \\
\hline 4 & GB-15a & 7 & 3.1 & 3.7 & - & - & - \\
\hline 5 & GB-16a & 7 & 4.0 & 3.5 & 6.2 & 55 & 5.9 \\
\hline 6 & GH-1a & 7 & 2.6 & 3.4 & - & - & - \\
\hline 7 & GH-9d & 7 & 3.9 & 4.2 & 7.0 & 79 & 5.1 \\
\hline 8 & GH-10b & 7 & 2.2 & 2.8 & - & - & - \\
\hline 9 & GM-3a & 7 & 4.0 & 4.3 & - & - & - \\
\hline 10 & GM-3b & 7 & 2.0 & 3.5 & 3.2 & 60 & 5.7 \\
\hline 11 & GM-4a & 7 & 2.5 & 4.0 & - & - & - \\
\hline 12 & GM-7a & 7 & 3.2 & 4.1 & - & - & - \\
\hline 13 & GM-11a & 7 & 3.5 & 4.0 & 4.3 & 22 & 6.5 \\
\hline 14 & GM-14a & 7 & 2.9 & 3.6 & 5.0 & 72 & 5.3 \\
\hline
\end{tabular}




\section{Characterization of rhizobia using Gram's staining and peptone water test}

A total of 14 rhizobial isolates obtained from different nodules of cluster bean plants were characterized by using Gram staining and peptone water test. It was observed that all the isolates were found to be Gram -ve with small rods shape (Fig. 3). Gram -ve reaction and Congo red dye absorption by bacteria during the isolation process are one of the typical characteristics of rhizobial strains (Abere et al., 2009). For peptone water test, all the isolates were inoculated in test tubes containing $5 \mathrm{ml}$ peptone water broth and incubated at $30^{\circ} \mathrm{C}$ temperature for 3-4 days to observe the growth of the isolates. All rhizobial isolates showed growth in the above broth indicating the purity of rhizobia (Fig. 2). Thus, on the basis of Gram staining and peptone water test, all 14 rhizobial isolates were selected for phosphate solubilization.

Screening of rhizobial isolates for Psolubilization

Out of the 14 rhizobial isolates, seven isolates produced clear zone of solubilization surrounding the colonies after seven days of incubation on Pikovskaya's medium. All the rhizobia could not solubilize phosphate was also reported earlier by (Halder and Chakrabarthy, 1993; Alikhani et al., 2006; Daimon et al., 2006) indicating that phosphate solubilization is not a wide spread character and common among rhizobia.

The zone of solubilization increased up to seven days of incubation and decreased thereafter in all the rhizobia tested. Whereas the size of the colony increased up to four days of incubation and with no considerable change thereafter, up to seven days of incubation. Though zone of solubilization showed progressive increase with increase in incubation period, the colony did not show any proportionate increase in growth. The data on colony diameter, zone of solubilization, solubilization efficiency and final $\mathrm{pH}$ of the medium is presented in Table 3. Highest solubilization of phosphorous with zone of 7.0 $\mathrm{mm}$ diameter was recorded in the rhizobial isolate $\mathrm{GH}-9 \mathrm{~d}$ followed by isolate GB-16a with $6.2 \mathrm{~mm}$. The least zone of solubilization with $3.2 \mathrm{~mm}$ diameter was recorded in the isolate GM-3b. Maximum solubilization efficiency of $79 \%$ was recorded with the isolate $\mathrm{GH}-9 \mathrm{~d}$ while it is between $22-72 \%$ in rest of the isolates.

In the present study, rhizobial isolate GH-9d were proved to be better in phosphate solubilization. This indicates that the rhizobial strains exhibit much variation in phosphate solubilization and is probably related to the host and environmental factors.

Reduction in $\mathrm{pH}$ of the medium during solubilization was commonly observed in all isolates, with maximum reduction up to 5.1 was recorded in strain GH-9d.

This decrease in $\mathrm{pH}$ is a basic principle in phosphate solubilization and may be related to the production of organic acids (Sridevi and Mallaiah, 2009) and the release of protons (Chen et al., 2006). This type of negative correlation between phosphate solubilization and $\mathrm{pH}$ by rhizobial strains was reported earlier also (Sridevi and Mallaiah, 2009).

In the present study, rhizobium was isolated from soil samples collected from arid and semiarids regions of Haryana and was tested for their ability to support plant growth in terms of enhancing phosphorus availability. Seven rhizobium isolates produced clear zone of solubilization surrounding the colonies strains and are capable for solubilizing native phosphorus and enhances plant growth. Thus, these rhizobium isolates may be used in the production of efficient biofertilizers and hence generate a new scope for extensive research in the field of biofertilizers.

\section{References}

Abere, M., Heluf, G., and Fassil, A. 2009. Symbiotic effectiveness and 
characterization of Rhizobium strains of faba bean (Viciafaba L.) collected from eastern and western Hararghe highlands of Ethiopia. Ethiopian J. of Natural Res., 11, 223-244.

Alam, S., Khalil, S.N., and Rashid, A.M. 2002. In vitro solubilization of inorganic phosphate by phosphate solubilizing microorganism (PSM) from maize rhizosphere. Intl. J. Agric. Biol., 4, 454458.

Alikhani, H.A., Saleh-Rastin, N., Antoun, H. 2006. Phosphate solubilization activity of rhizobia native to Iranian soils. Plant and Soil, 287, 35-41.

Antoun, H. 2012. Beneficial microorganisms for the sustainable use of phosphates in agriculture. Procedia Eng., 46, 62-67.

Ashraf, M.Y., Akhtar, K., Sarwar, G.and Ashraf, M. 2005. Role of the Rooting System in Salt Tolerance Potential of Different Guar Accessions. Agron. for Sustain. Develop., 25, 243-249.

Castro, V., Ferreira, E.M., McGrat, S.P. 2003. Survival and plasmid stability of rhizobia introduced into a contaminated soil. Soil Biol. Biochem., 35, 49-54.

Chen, Y.P., Rekha, P.D. and Arun, A.B. 2006. Phosphate solubilizing bacteria from subtropical soil and their tricalcium phosphate solubilizing abilities. Applied Soil Ecol., 34, 33-41.

Daimon, H., Nobuta, K., and Ohe, M. 2006. Tricalcium phosphate solubilization by root nodule bacteria of Sesbania cannabina and Crotalaria juncea, Plant Prod. Sci., 9, 388-389.

Elsheikh, E.A.E. and Ibrahim, K.A 1999. The Effect of Bradyrhizobium Inoculation on Yield and Seed Quality of Guar (Cyamopsis tetragonoloba L.). Food Chemist., 65, 183-187.

Francois, L.E., Donovan, T.J., and Maas, E.V. 1990. Salinity Effects on Emergence, Vegetative Growth and Seed Yield of Guar. Agron. J., 82, 587-592.

Geniaux, E., Laguerre, G., and Amarger, N. 1993. Comparison of geographically distant populations of Rhizobium isolated from root nodules of Phaseolus vulgaris. Mol. Ecol., 2, 295-302.

Gothwal, R.K., Nigam, V.K., Sasmal, D., and Ghosh, P. 2006. Phosphate solubilization by rhizospheric bacterial isolates from economically important desert plants. Indian J. Microbiol., 46 (4), 355-361.

Gresta, F., Luca, A.D., Strano, A., Falcone, G., Santonoceto, C., Anastasi, U., and Gulisano, G. 2014. Economic and Environmental Sustainability Analysis of Guar (Cyamopsis tetragonoloba L.) Farming Process in a Mediterranean Area: Two Case Studies. Italian J. of Agron., 9, 20-24.

Halder, A.K., and Chakrabarthy P.K. 1993. Solubilization of inorganic phosphate by Rhizobium", Folia Microbiol., 38, 325330.

Handley, B.A., Hedges, A.J., and Beringer, J.E. 1998. Importance of host plants for detecting the population diversity of Rhizobium leguminosarum biovar viciae in soil. Soil Biol. \& Bio., 30, 241-249.

Jadhav, R.N. 2013. Isolation of rhizobia from soybean cultivated in latur area and study of its phosphate solubilization activity. Biosci. Discovery, 4(1), 100-103.

Kalyani, D.L. 2012. Performance of Cluster Bean Genotypes under Varied Time of Sowing. Legume Res., 35, 154-158.

Khan, A.A., Jilani, G., and Akthar, M.S. 2009. Phosphorous Solubilizing Bacteria: Occurrence, Mechanism and their Role in Crop Production. J. Agric. Biol. Sci., 1(1), 48-58.

Kiers, E.T., Rousseau, R.A., West, S.A., and Denison R.F. 2003. Host sanctions and the legume-rhizobium mutualism. Nature, 425, 79-81.

Kucuk, C., Kivanç M., and Kinaci E. 2006. Characterization of Rhizobium Sp. Isolated from Bean. Turk J. Biol., 30, 127-132.

Nautiyal, C.S. 1999. An efficient microbiological growth medium for screening phosphate solubilizing microorganisms. FEMS Microbiol. Lett., 170, 265-270. 
Pathak, S.K., Singh, M. and Henry, A. 2010. Molecular assessment of genetic diversity in clusterbean (Cyamopsis tetragonoloba) genotypes. J. Genet., 89, 243-246.

Peix, A., Rivas-Boyero, A.A., Mateos, P.F., Rodriguez, C.B., Molina, E.M., and Velazquez 2001. Growth promotion of Chick pea and Barley by a phosphate solubilizing strain of Mesorhizobium mediterraneum under growth chamber conditions. Soil Biol. Biochem., 33, 103110.

Perez, E., Sulbaran, M., Ball, M.M., and Yarzabal, L.A. 2007. Isolation and characterization of mineral phosphatesolubilizing bacteria naturally colonizing a limonitic crust in the south-eastern Venezuelan region. Soil Biol. Biochem., 39, 2905-2914.

Pikovskaya, R.I. 1948. Mobilization of phosphorous in soil connection with the vital activity of some microbial species. Microbiol., 17, 362-370.

Ribeiro, C.M., and Cardoso, E.J.B.N. 2012. Isolation, selection and characterization of rootassociated growth promoting bacteria in Brazil pine (Araucaria angustifolia). Microbiol Res., 167, 69-78.

Rodriguez, H., and Fraga, R. 1999. Phosphate solubilizing bacteria and their role in plant growth promotion. Biotechnol Adv., 17, 319-339.

Ruzhen, J., and Peng Y. 2010. Preliminary Study on phosphate solubilization and Kreleasing abilities of Rhizobium tropici Martinez-Romero et al., strains from woody legumes. In 19th World Congress of Soil Science, Soil Solutions for a Changing World, 104-107.
Shaaban, S.H.A., El-Taweel, A.A., Osman, I.M.S., and El-Fouly, M.M. 2016. Nutritional status of soil and plant and nutrient discrimination factor of some irrigated olive orchards at the North West of Egypt. African J. of Agri. Res., 11 (34), 3232-3239.

Sridevi, M., and Mallaiah K.V. 2009. Phosphate solubilization by Rhizobium strains. India J. Microbiol., 49, 98-102.

Srivastava, S., Yadav, K.S., and Kundu, B.S. 2004. Prospects of using phosphate solubilizing Pseudomonas as biofungicide". Indian J. Microbiol., 44, 91-94.

Tripp, L.D., Lovelace, D.A., and Boring, E.P. 2011. Keys to Profitable Guar Production. Texas Agricultural Experimental Station Bulletin, 7-11.

Tucker, B., and Foraker, R. 1975. Cotton and Grain Sorghum Yields Following Guar and Cowpeas Compared to Continuous Cropping. Oklahoma Agricultural Experimental Station Research, 728.

Ullah, I., Khan, A.R., Park, G.S., Lim, J.H., Waqas, M., Lee, I.J., and Shin, J.H. 2013. Analysis of phytohormones and phosphate solubilization in Photorhabdus spp. Food Sci. Biotechnol., 22, 25-31.

Undersander, D.J., Putnam, D.H., Kaminski, A.R., Kelling, K.A., Doll, J.D., Oplinger, E.S., and Gunsolus, J.L. 1991. Guar. Alternative Field Crops Manual. Uni. of Wisconsin-Extension.

Vincent, J.M. 1970. A manual for the practical study of root nodule bacteria. In: IBP Handbook No. 15. Blackwell Scientific Publications, Oxford, England, 73-97.

\section{How to cite this article:}

Subha Dhull, Rajesh Gera, Hardeep Singh Sheoran and Ridham Kakar. 2018. Phosphate Solubilization Activity of Rhizobial Strains Isolated From Root Nodule of Cluster Bean Plant Native to Indian Soils. Int.J.Curr.Microbiol.App.Sci. 7(04): 255-266. doi: https://doi.org/10.20546/ijcmas.2018.704.029 